\title{
Letters
}

Website: bmj.com

Email: letters@bmj.com

\section{Discomfort of patient power}

\section{Patients are not doctors' equals}

EDITOR-Smith in his editorial on the discomfort of patient power says that there is no "truth" defined by experts. ${ }^{1}$ Coulter reports that doctors and patients are equals with different expertise. ${ }^{2}$ The government's working group on chronic fatigue syndrome and myalgic encephalomyelitis wove patients' assertions into the scientific research in its report. ${ }^{3}$

It is absurd to say that there is no truth defined by experts, that patients are equals, or allow patients to define conditions and treatment. Although criticism of medical hubris is important, this is a denial of the nature of medicine. Clinical effectiveness depends on understanding the patient's beliefs and expectations. Patients are, however, not equals, and their beliefs do not have the ontological status of medical knowledge.

Denial of the status of doctors and of medicine's tradition of research is false democracy. It is an attempt to avoid destructive envy. Destructive envy denigrates and spoils that which is needed, biting the hand that feeds us or cutting off one's nose to spite one's face. More than other professional groups, doctors are envied. Partly this derives from the inequality of the relation-

\section{Advice to authors}

We prefer to receive all responses electronically, sent directly to our website. Processing your letter will be delayed unless it arrives in an electronic form.

We are now posting all direct submissions to our website within 24 hours of receipt and our intention is to post all other electronic submissions there as well. All responses will be eligible for publication in the paper journal.

Responses should be under 400 words and relate to articles published in the preceding month. They should include $\leqslant 5$ references, in the Vancouver style, including one to the BMJ article to which they relate. We welcome illustrations.

Please supply each author's current appointment and full address, and a phone or fax number or email address for the corresponding author. We ask authors to declare any competing interest. Please send a stamped addressed envelope if you would like to know whether your letter has been accepted or rejected.

Letters will be edited and may be shortened.

bmj.com

letters@bmj.com ship between doctors and patients. It can be difficult to tolerate powerlessness, ignorance, dependence, needing help, and being helped. For doctors it is difficult having their attempts to help spoiled by the patient. It is easier to feign uncertainty or powerlessness and comply with patients' demands. But this attempt to avoid envy leads talented doctors to deny their skills, knowledge, and authority. Placatory goodwill abounds but addressing the painful problems of the patient is hindered. ${ }^{4}$

Often patients come demanding investigations, referrals, or treatments. Acquiescence leads to further demands and feelings of desperation in the doctor. Attendant is the risk of unnecessary, harmful interventions, just to do something. ${ }^{5}$ One can endlessly improve one's consulting skills or be more patient centred, but the envy doesn't go away. These patients strive to undermine their doctor's skill, knowledge, and concern. This is not restricted to just a minority of manifestly antisocial patients.

Understanding the destructive forces in the doctor-patient relationship is essential. The bland pseudodemocratic niceties in the $B M J$ are no substitute for understanding the dynamics of the consultation or the legal and social changes affecting the health service, neither do they enable us to work in the best interests of our patients.

Daniel McQueen general practitioner

Brighton BN1 6EG

daniel.mcqueen@virgin.net

1 Smith R. The discomfort of patient power. BM] 2002;324:497-8. (2 March.)

2 Coulter A. After Bristol: putting patients at the centre. $B M$ 2002;324:648-51. (16 March.)

Eaton L. Recognising chronic fatigue is the key to improving outcomes. BMJ 2002;324:131. (19 January.)

4 Main T. Some psychodynamics of large groups. In: Kreege L. The large group. London: Constable, 1975.

5 Winnicott DW. Hate in the countertransference. Int J Psycho Analysis 1949;30:69-74.

\section{Power sharing is not a takeover bid}

EDITOR-Smith discussed the discomfort of patient power. ${ }^{1}$ Having declared a conflict of interest-I am one of the clinicians who resigned from the working group that reported to the chief medical officer on chronic fatigue syndrome and myalgic encephalomyelitis-I hope the following clinical anecdotes may inform this debate. ${ }^{2}$

Many patients who attend my chronic fatigue clinic had heard of or read the report. Many welcomed the official recognition of chronic fatigue syndrome as a discrete and "genuine" illness, having suffered years of doubt by others and also self doubt. The downside included the negative interpretations patients took from the report regarding the relationship between mind and body and getting better. One patient demanded to be referred to an immunologist since the government said myalgic encephalomyelitis was physical. Two others said how depressed they felt reading that there was no cure, and doubted my previous assurance that they would probably improve notably and possibly be cured. Several were confused that the report advised active rehabilitation therapies, such as graded exercise therapy and cognitive behaviour therapy, alongside the more passive approach of pacing.

I am absolutely convinced that doctors should enter into an alliance with their patients on equal terms, with one having more general knowledge and the other more personal knowledge of illness. Successful therapeutic relationships depend on each party sharing their knowledge. This is why I almost always send my patients a copy of any letter I write concerning them. ${ }^{3}$ Giving our patients the power of that knowledge allows them to share the responsibility of getting better with the doctor, rather than expecting passively applied medical miracles.

But this is power sharing, not a takeover. Takeovers produce polemic rather than a balanced view. As human beings we already make most decisions on emotional rather than rational grounds, as shown by the debate about the vaccine for measles, mumps, and rubella. As doctors we should present the rational and practical choices to our patients so they can use both the power of that knowledge as well as their own intuition to decide what is best for them and their families.

Peter D White senior lecturer in psychological medicine

Barts and The London, Queen Mary School of Medicine and Dentistry, London EC1A 7BE p.d.white@qmul.ac.uk

\footnotetext{
1 Smith R. The discomfort of patient power. BMJ 2002;324:497-8. (2 March.)

2 Independent Working Party. A report of the CFS/ME working group to the chief medical officer. Report to the chief medical officer of an independent working group. London: Stationery officer of an independent working group. London: Stationery
Office, 2002. (www.doh.gov.uk/cmo/cfsmereport/ index $(\mathrm{m})$

3 White PD. Solutions to stigma: sharing knowledge with the patient: In: Crisp $\mathrm{AH}$, ed. Every family in the land: understanding prejudice and discrimination against people with mental illness. London: Royal Society of Medicine, Royal Society of Psychiatrists, Sir Robert Mond Memorial Trust, 2001. Available at: wwwstigma 23 April 2002).
} 


\section{Are choices irrational or doctors and patients misinformed?}

EDITOR - Smith in his editorial raises many important and valid points regarding risk assessment and decision making by patients. ${ }^{1}$ We must respect the autonomy and choice of patients, an issue recently raised by the secretary of state for health, Alan Milburn, in a speech to the new health network, which stated that patients have a right to be involved in their care. ${ }^{2}$

Smith is correct in his description of risk assessment, with its complex mix of statistical information coupled with uncertainty regarding consequences. But when patients ask doctors for information to help them come to decisions, this is most often offered in terms of numerical probability information. ${ }^{3}$ Although misinformation does not necessarily result in an inappropriate or incorrect choice by patients, we must recognise difficulties in how doctors interpret this information themselves as well as its delivery and understanding by patients. The use of numerical probability information by doctors often varies because of individual interpretations of available evidence, and doctors themselves may misunderstand these numerical data. ${ }^{5}$

In view of differing information from clinicians (often misinterpreted) and coupled with patients' individual approaches to risk, it is easy to see how patients' choices might seem inappropriate. Before labelling patient choices as irrational, we must first examine how clinicians themselves understand information on probability, and whether the methods used to deliver this information to patients are effective in order to optimise patient choice.

Richard Fuller specialist registrar in elderly medicine St James's University Hospital, Leeds LS9 7TF Ftworf@aol.com

1 Smith R. The discomfort of patient power. $B M J$ 2002;324:497-8. (2 March.)

2 Department of Health. Redefining the National Health Service-Speech by Rt Hon Alan Milburn MP, Secretary of State for Health to the New Health Network. 15 January 2002. London: DoH, 2002.www.doh.gov.uk/speeches/ jan2002milburnnhn.htm (accessed 23 Apr 2002).

3 Kalet A, Roberts JC, Fletcher R. How do physicians talk with their patients about risks? I Gen Intern Med 1994:9:402-4.

4 Buckholtz WM. Competent patients and irrational choices. New Engl J Med 1990;323:1354

5 Bryant GD, Norman GR. Expressions of probability: words and numbers. New Engl J Med 1980;302:411.

\section{Personal choice yes, but not at others' cost}

EDITOR-Smith has, by accepting individual choice of medical treatment as an inevitable consequence of postmodernism, even if that choice is not based on scientific evidence, raised an important issue that threatens our publically funded healthcare system. ${ }^{1}$

Doctors have, for better or worse, accepted the role of arbiters of need using the criterion of scientific evidence of effectiveness. If I choose a treatment that is not recommended by my doctor or based on the best evidence of effectiveness can I reasonably expect other taxpayers to pay for it? And, in view of the recent evidence published in the same issue of the $B M J$ that homoeopathy is ineffective can taxpayers be expected to fund it?

Michael C Sharpe consultant

Royal Edinburgh Hospital, Edinburgh EH10 5HF michael.sharpe@ed.ac.uk

1 Smith R. The discomfort of patient power. $B M$ 2002:324:497-8. (2 March.)

2 Lewith GT, Watkins AD, Hyland ME, Shaw S, Broomfield JA, Dolan G, et al. Use of ultramolecular potencies of allergen to treat asthmatic people allergic to house dust mite: double blind randomised controlled clinical trial. $B M$ J 2002;324:520. (2 March.)

\section{Questions for Dr Foster}

EDITOR-I was interested in two aspects of Little's article. ${ }^{1}$ One is that the motivation for setting up the Dr Foster organisation came from a "particularly horrendous experience" in a maternity unit. This implies an agenda that is not limited to the objective gathering of data.

The second is the funding. I've been interested that a small organisation can apparently gather data that official bodiessuch as the Department of Health-find too difficult or too expensive to obtain. Does Dr Foster pay NHS trusts for their time and trouble in gathering the data that it sells on? Does the Department of Health provide it with free information? Does Dr Foster publish a list of the organisations who have underwritten it? Little's words seemed very carefully chosen when she quoted what Dr Foster said about its financial backers.

James O Drife professor of obstetrics and gynaecology General Infirmary, Leeds LS2 9NS

j.o.drife@leeds.ac.uk

1 Little R. Publishing: a doctor's guide to Dr Foster. $B M$ J 2002;324:552. (2 March.2002.)

\section{Medical emergency teams and cardiac arrests in hospital}

\section{Results may have been due to education} of ward staff

EDITOR-Proof that a medical emergency team can reduce the incidence of and mortality from unexpected cardiac arrest is eagerly awaited, as such a proposal is intuitive. However, the number of such arrests can be influenced by several factors, including the number of "do not resuscitate" decisions made. Buist et al's paper fails to take this into account, and suffers from other methodological errors too. ${ }^{1}$

The study used a historical control group and was undertaken in a setting in which there was already a trend towards a reduced incidence of and mortality from cardiac arrest. Moreover, the case mix varied considerably between the two study periods. The authors' definition of cardiac arrest included patients who had not actually experienced an arrest yet excluded four who had been allocated do not resuscitate orders but for whom a call was made. Ward patients who do not have a cardiac arrest have a better outcome than those who do; hence by adopting a loose definition the study denominator has been artificially enhanced, giving a false benefit.

Some patients receive cardiopulmonary resuscitation despite it being futile, and thus the resuscitation status of critically ill patients must be established. However, any increase in do not resuscitate orders inevitably reduces the incidence of and mortality from unexpected cardiac arrests. The introduction of a medical emergency team increases the number of do not resuscitate orders. ${ }^{2}$ Buist et al report that, in 1999, the medical emergency team made 13 such orders for patients who subsequently died but do not report the overall incidence of these orders in the hospital in either year studied.

The study's design makes it impossible to separate the beneficial impact of the formal education process provided to ward staff from that due to specific interventions by the medical emergency team. The education may have led to better ward care or to more do not resuscitate orders being applied by staff who were not members of the team. Perhaps education alone led to the results that are being attributed to the team.

The cover of the issue of the $B M J$ containing Buist et al's paper, showing a medical emergency team in action, suggests that the authors have confirmed a beneficial role for the team. This may be correct, as the team may have reduced the number of inappropriate cardiac arrest calls by increasing the incidence of do not resuscitate orders or by improving the education of ward staff. What is not proved is that a medical emergency team can reduce the incidence of and mortality from unexpected cardiac arrest.

Gary B Smith consultant in intensive care medicine Portsmouth Hospitals NHS Trust, Portsmouth PO6 3LY gary.smith@porthosp.nhs.uk

Jerry Nolan consultant in anaesthesia and intensive care Royal United Hospital, Bath BA1 3NG

1 Buist MD, Moore GE, Bernard SA, Waxman BP, Anderso JN, Nguyen TV. Effects of a medical emergency team on reduction of incidence of and mortality from unexpected cardiac arrests in hospital: preliminary study. BMJ 2002;324:387-90. (16 February)

2 Parr MJA, Hadfield JH, Flabouris A, Bishop G, Hillman K. The medical emergency team: 12 month analysis of reasons for activation, immediate outcome and not-forresuscitation orders. Resuscitation 2001;50:39-44.

\section{Bottom up approach works too}

EDIToR-Like Buist et al, ${ }^{1}$ we have recognised that care preceding admission to the intensive care unit can be improved. ${ }^{2}$ To do this we chose a combination of a bedside physiology based scoring system, ${ }^{3}$ increased education of both nurses and doctors in the recognition of critically ill patients, and use of "outreach" nurses with skill in intensive care who can both support patients on the ward and help with their admission to the intensive care unit.

This initiative was backed by a protocol that ensured escalation of care if the patient was not improving and was for resuscitation. This bottom up approach, which contrasts with Buist et al's use of specialists who are 
"parachuted in," was welcomed by nurses and junior doctors, who were empowered to call for help. The physiology based scoring system was applied to 2000 surgical patients and identified all patients who went on to die in hospital well before they did so. The clear protocol for responding to these patients set standards that could easily be audited.

Before and after studies such as Buist et al's will always be vulnerable to failure to measure confounders. Were more patients allocated "do not resuscitate" orders with and without involvement of the medical emergency team, and did the intensive care unit change its admission policy? It would have helped if secular trends in similar hospitals had been measured, but conducting a randomised controlled trial of a mixed educational and therapeutic intervention in which one of the treatment outcomes is intensive treatment is extremely difficult and some would argue unethical.

Surely the question is not whether knowledgeable staff should see patients with physiological problems early and involve more senior staff if they are not improving but rather how such a service should be delivered. Andrew King surgical research fellow
atk1@soton.ac.uk

Peter Pockney surgical research fellow

Mick Nielsen consultant in intensive car

Maureen Coombes nurse consultant in intensive care Ian Bailey consultant general surgeon

Mike Clancy consultant in emergency medicine

Southampton University Hospitals Trust, Mailpoint 816 , Southampton SO16 6YD

1 Buist MD, Moore GE, Bernard SA, Waxman BP, Anderson JN, Nguyen TV. Effects of a medical emergency team on reduction of incidence of and mortality from unexpected cardiac arrests in hospital: preliminary study. $B M$ 2002;324:387-90. (16 February.)

2 McQuillan P, Pilkington S, Allan A, Taylor B, Short A, Morgan $\mathrm{G}$, et al. Confidential inquiry into quality of care before admission to intensive care. BMJ 1998:316:1853-8.

3 Stenhouse C, Coates S, Tivey M, Allsop P, Parker T Prospective evalution to aid earlier detection of patients developing score illness on a general surgical ward. Br J Anaesth 2000;663P.

\section{Authors' reply}

EDITOR-We suspect that Smith and Nolan may be kept waiting some time for absolute proof that medical emergency teams can reduce the incidence of and mortality from cardiac arrest in hospital. As they point out, our study, which was done in a single hospital with a historical control group and an unblinded intervention and analysis, is well short of the gold standard for randomised controlled trials.

We believe that an intervention such as a hospital wide medical emergency team is hard to evaluate by a randomised controlled trial in a single institution. Some of the shortcomings of our study may be addressed by the forthcoming multicentre randomised cluster control study of a medical emergency team intervention. This study (the MERIT study), which is being undertaken under the auspices of the Australian and New Zealand Intensive Care Society Clinical Trials Group, will randomise an intervention by a medical emergency team in clusters to over 30 participating hospitals throughout Australia and New Zealand.

We would accept Smith and Nolan's comment concerning the effect of "do not resuscitate" orders on the incidence of cardiac arrest in hospital. However, we think that if the medical emergency team increased the rates of such orders throughout the hospital and thus reduced the incidence of cardiac arrest this would be a positive effect of the medical emergency team system. As pointed out, we did not measure this; furthermore, we are unaware of any data that support this contention, despite the reference to a study by Parr et al (M J A Parr, personal communication).

Finally, with respect to the case mix; although the number of planned admissions did increase, the number of emergency admissions also increased, but by a much larger absolute number. In fact, most of the increase in planned admissions arose through better management of the "others" category (mostly direct admissions from private specialists), which reduced dramatically over the study period. As in any acute care hospital, over time our patient population has become older with more severe illness.

We agree with King et al that a top down approach to some of these issues will not greatly alter the nature of the nurses' and junior doctors' interaction with patients. There is still much to do in identifying patients at risk, developing systems for scoring severity of illness of hospital inpatients, and developing education packages for our junior medical and nursing staffs.

Michael Buist director of intensive care unit acmdbuist@bigpond.com

Gaye Moore research nurse

Stephen Bernard deputy director of intensive care unit

Bruce Waxman surgical programme director Departments of Surgery and Intensive Care, Dandenong Hospital, Dandenong, Victoria 3175 , Australia

Tuan Nguyen senior research fellow

Garvan Institute of Medical Research, Darlinghurst, New South Wales 2010, Australia

Jeremy Anderson associate professor

Monash Institute of Public Health, Clayton, Victoria 3168 1 Parr MJA, Hadfield JH, Flabouris A, Bishop G, Hillman K.
The medical emergency team: 12 month analysis of
reasons for activation, immediate outcome and not-for-
resuscitation orders. Resuscitation 2001;50:39-44.

\section{Was it a heart attack?}

\section{Troponin measurement is not} straightforward

EDITOR-McKenna and Forfar describe how the proposed redefinition of myocardial infarction has made the measurement of cardiac specific troponin central to its diagnosis. ${ }^{1}$ In a patient presenting with chest pain a troponin concentration above the 99th centile of normal is now sufficient to diagnose myocardial infarction, irrespective of any electrocardiographic changes. Previously, as the authors state, a patient had to show the development of $\mathrm{Q}$ waves on electrocardiography or an increase in creatine kinase activity to more than twice the upper reference limit before this judgment was made. The widespread introduction of troponin $\mathrm{T}$ and troponin I measurements is an undoubted improvement, but limitations exist with the assays, which most clinicians are unaware of and may give rise to diagnostic difficulties.

One issue concerns the use of the 99th centile of normal as the cut off point for myocardial infarction. Most assays are not sensitive enough to measure values as low as this. For example, the 99th centile for troponin T (Roche Diagnostics, Lewes, UK) is about $0.01 \mu \mathrm{g} / \mathrm{l}$, but the laboratory assay in routine use is unable to measure reliably below $0.03 \mu \mathrm{g} / \mathrm{l}$. This means that patients with troponin $\mathrm{T}$ concentrations between $0.01 \mu \mathrm{g} / \mathrm{l}$ and $0.03 \mu \mathrm{g} / \mathrm{l}$, who would be defined by the new criteria as having had a myocardial infarction, are currently being missed and included in the low risk category. McKenna and Forfar mention the use of bedside as opposed to laboratory troponin measurement, but near patient tests are less sensitive again, with the troponin T example being suitable for measurement only down to $0.1 \mu \mathrm{g} / \mathrm{l}$.

A second issue is that troponin measurement involves immunoassay analytical techniques as opposed to the more robust enzymatic methods used with traditional cardiac markers such as creatine kinase. As Ismail and Barth pointed out, immunoassay methods can-unpredictably-lead to wrong results in some people and in the context of troponins these are likely to be difficult to identify. $^{2}$

These and other limitations of troponin assays should not detract from the value they provide in most patients tested. They do raise concerns, however, if these tests are being used as the sole means of diagnosing myocardial infarction in a patient presenting with chest pain.

Eric S Kilpatrick consultant in chemical pathology Hull Royal Infirmary, Hull HU3 2JZ eric_kilpatrick@hotmail.com

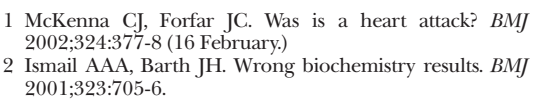

Variations in access to and interpretation of troponin assays are wide

EDITOR-Cardiospecific markers, such as troponin $\mathrm{T}$ and troponin $\mathrm{I}$ and creatine kinase MB are more sensitive than creatine kinase in detecting ischaemic myocardial necrosis and predicting prognosis in acute coronary syndromes and coronary interventions. ${ }^{1-3}$ In 2000 a joint committee of the European Society of Cardiology and American College of Cardiology recommended changing the diagnostic criteria for acute myocardial infarction to take account of these findings. ${ }^{4}$

According to the new criteria, acute myocardial infarction should be diagnosed by a raised concentration of troponin $\mathrm{T}$, troponin I, or creatine kinase in addition to 
typical symptoms, changes on electrocardiography, or coronary intervention. Even minor amounts of myocardial necrosis would thus be classified as myocardial infarction. As a result, some patients previously diagnosed as having unstable angina will instead be classified as having acute myocardial infarction.

Changes to the diagnostic criteria may lead to misinterpretation of epidemiological studies and clinical audits in which trends are analysed over time. ${ }^{5}$ Furthermore, piecemeal implementation of the new criteria may lead to erroneous comparisons between hospitals, particularly in respect of clinical indicators by which standards of care are often judged.

We undertook a postal survey of all 71 cardiologists and physicians with an interest in cardiology in Scotland to determine whether they currently have access to troponin $\mathrm{T}$, troponin I, or creatine kinase MB assays, and whether the new criteria for acute myocardial infarction are being implemented in their units. Sixty four $(90 \%)$ clinicians responded, providing at least one response from each of the 29 relevant hospitals. Five respondents had no access to troponin or creatine kinase $\mathrm{MB}$ assays. Twenty two had access to troponin T, 23 to troponin I, and 27 to creatine kinase MB. Access was often by special request only. Of the 59 respondents with access to at least one assay, only $36(61 \%)$ routinely used it for all patients presenting with possible acute myocardial infarction.

Across Scotland percutaneous coronary interventions are undertaken in six NHS cardiac catheterisation laboratories. In two, troponin concentrations were checked routinely after all procedures. In the remaining four, they were checked only in selected patients. There was no consensus on the diagnostic label that should be given to a patient presenting with typical chest pain who had a significant rise in troponin in the absence of typical electrocardiogram changes or a significant rise in cardiac enzymes. Twenty respondents diagnosed myocardial infarction, 25 unstable angina, and 17 used the non-specific label of acute coronary syndrome.

Clinicians and hospitals are currently adopting the new criteria inconsistently. All clinicians need to have access to assays for cardiospecific markers, and consistent interpretation of the results is essential to prevent epidemiological chaos.

Alastair C H Pell consultant cardiologist Monklands Hospital, Airdrie ML6 0JS

Jill P Pell consultant in public health medicine Greater Glasgow NHS Board, Glasgow G3 8YU jill.pell@gghb.scot.nhs.uk

1 Antman EM, Grudzien C, Mitchell RN, Sacks DB Detection of unsuspected myocardial necrosis by rapid bedside assay for cardiac troponin T. Am Heart $J$ 1997;133:596-8

2 Apple FS, Falahati A, Paulson PR, Miller E, Sharkey SW. Improved detection of minor ischemic myocardial injury with measurement of serum cardiac troponin I. Clin Chem 1997;43:2047-51.

3 Tardiff BE, Califf RM, Tcheng JE, et al. for the IMPACT-II Investigators Clinical outcons after detection of eva enzymes in patients undergoing percuted tion: IMPACT-II trial (Integrilin [eptifibattide] to Minimize
Platelet Aggregation and Coronary Thrombosis-II). J Am Coll Cardiol 1999;33:88-96.

4 Joint European Society of Cardiology/American College of Cardiology Committee. Myocardial infarction redefined - a consensus document of the Joint European Society of Cardiology/American College of Cardiology Committe for the Redefinition of Myocardial Infarction. Eur Heart 2000;21:1502-13 and J Am Coll Cardiol 2000;36:959-69.

5 Tunstall-Pedoe H. Comment on the ESC/ACC Redefinition of myocardial infarction by a consensus dissenter $E$ ir Heart I 2001;29:613-5 and I Am Coll Cardiol 2001; 37:1472-4.

\section{New score is needed to predict risk of coronary heart disease}

EDITOR-McManus et al show the difficulties inherent in using currently available risk scoring systems for cardiovascular disease, with only moderate agreement between methods. ${ }^{1}$ They also show the methods' relatively low accuracy when compared with independently calculated Framingham risk estimates.

Much of the inaccuracy was due to a lack of risk factor information in case records and use of risk scoring in people with diagnosed cardiovascular disease, who should be considered at high risk and treated accordingly. As in previous comparison studies, the Framingham risk equations were used as the gold standard by which the performance of all the Framingham derived risk assessment tools was evaluated. ${ }^{2}$

Important treatment decisions are being based on the findings of risk assessment tools. Surprisingly, little effort has been put into assessing the accuracy of the Framingham risk score in contemporary European populations. Haq et al simply examined agreement between the Framingham risk score and other northern European risk scores but did not compare the estimated with observed risk of events. ${ }^{3}$

In a Scottish primary prevention trial the observed incidence of coronary heart disease events in the placebo arm of the trial was noted to be "close to that predicted by the Framingham regression function." Unlike the Framingham prediction, however, the outcomes in the trial included angina and peripheral vascular disease Comparisons are also made difficult because the methods of classifying risk factors vary between the Framingham study and subse-

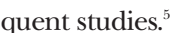

We were surprised that all of the patients studied had data on left ventricular hypertrophy available, which would require coding of an electrocardiogram to be comparable with Framingham data; from our experience this is rarely done in general practice. Depending on which risk score a practice uses and who does the work, appreciable differences in the prevalence of high risk patients will result, together with commensurate differences in workload and prescribing costs. General practitioners using the European table's sensitivity and specificity estimates reported by McManus et al, and assuming a prevalence of high risk patients of $10 \%$, will declare $31 \%$ of patients as at high risk largely because of the low specificity of the table. By contrast, nurses using the British programme will find that only $8 \%$ of patients are at high risk.

Although the national service framework considers all the risk scoring systems examined by McManus et al to be acceptable, their performance varies considerably. A new, properly validated risk score is needed that can be completed with readily available information, preferably without the need for laboratory tests or an electrocardiogram.

Peter Brindle Wellcome training fellow in health services research, department of social medicine peter.brindle@bristol.ac.uk

Tom Fahey senior lecturer in general practice, division of primary health care

Shah Ebrahim professor in epidemiology of ageing, department of social medicine

University of Bristol, Bristol BS8 2PR

1 McManus RJ, Mant J, Meulendijks CFM, Salter RA, Pattison HM, Roalfe AK, et al on behalf of the Midlands Research Practice Consortium. Comparison of estimates and calculations of risk of coronary heart disease by doctors and nurses using different calculation tools in doctors and nurses using different calculation tools in general practice:

2 Anderson KM, Odell PM, Wilson PWF, Kannel WB

Anderson KM, Odell PM, Wilson PWF, Kannel WB,
Cardiovascular disease risk profiles. Am Heart J 1991, 121:293-8.

3 Haq IU, Ramsay LE, Yeo WW, Jackson PR, Wallis EJ. Is the Framingham risk function valid for northern European populations? A comparison of methods for estimating absolute coronary risk in high risk men. Heart 1999;81:40-6.

4 West of Scotland Coronary Prevention Study Group. Baseline risk factors and their association with outcome in the west of Scotland coronary prevention study. Am J Cardiol 1997;79:756-62.

5 Ramachandran S, French JM, Vanderpump MPJ, Croft P, Neary RH. Using the Framingham model to predict heart disease in United Kingdom: retrospective study. BMJ $2000 \cdot 320 \cdot 676-7$

\section{Using real patients in professional medical exams}

Suggestions would make examinations with real patients impractical

EDITOR-The paper by Sayer et al raises important issues for those responsible for developing and delivering undergraduate and postgraduate clinical examinations. ${ }^{1}$ Clearly most would want to include real patients, often alongside simulated patients, to enhance the validity of the examination, although obtaining suitable real patients has become harder recently.

No one would argue about the need to obtain informed consent or to ensure confidentiality of patient data. The issue of the available level of medical care, however, needs further consideration. If the source of patients includes inpatients then the environment in which the examination is conducted should offer nursing and medical support that would be available elsewhere in the hospital, and to a level appropriate to clinical need. Obviously the permission of the responsible doctor must be sought, and this should be granted only if the care available is adequate.

In many examinations, however, the patients may be outpatients, and this situation is quite different. There is no reason to believe that attending the examination is more likely to cause an adverse effect than would spending the day doing something else. In fact, should the patients 
be taken ill or their condition become unstable one could argue that it was their good fortune to be at the examination, where medical attention was more likely to be readily available than elsewhere.

The traditional places in which clinical examinations are conducted, such as wards and outpatient clinics, are becoming less likely to be made available by hospital trusts. Increasingly, purpose built clinical skills centres and other venues are being used, which may not be located on the same site as a hospital. I cannot see any reason why properly informed outpatients are at an increased risk through attending the examination or are much different from simulated patients, who may also be examined, in their need for complex medical facilities.

Common sense would dictate that first aid and resuscitation equipment should be available; that only patients whose condition was stable should be recruited; that patients should be instructed to bring their normal drugs with them; and that nursing and medical staff should be available during the examination. To go to some of the extremes suggested in the paper might make it impractical to continue clinical examinations using real patients, to the detriment of our attempts to ensure high quality assessment procedures.

David I Newble professor of medical education Department of Medical Education, University of Sheffield, Northern General Hospital, Sheffield S5 7AU

d.newble@shef.ac.uk

1 Sayer M, Bowman D, Evans D, Wessier A, Wood D. Use of patients in professional medical examinations: current UK
practice and the ethicolegal implications for medical edupractice and the ethicolegal implications for medical edu-
cation. BMJ 2002;324:404-7. (16 February.)

\section{Some patients use professional} examinations to get second opinions

EDITOR-Sayer et al emphasise the need to protect patients in medical examinations from both the physical consequences of their condition and the psychological consequences (for instance, inappropriate or incorrect medical advice given during the event). ${ }^{1}$ This-specifically, the parental wish for a second opinion-caught my attention when colleagues and I hosted the clinical part of the Royal College of Paediatrics and Child Health examination.

Sayer et al's paper was published just before we sent out our second reminder letter, which covered many of the points made. It included details of the candidate's five minute counselling session with the parents in front of the two long case examiners and what to do if the candidate gave incorrect or worrying information. So I was surprised to hear that three families were so excited by the prospect of their child getting another opinion from a young doctor, as well as two paediatricians whom they had never met before, that they had cancelled their routine follow up appointments.

Perhaps my reminder letter had been too enthusiastic. Or parents really did want another opinion. With this in mind, I wrote a questionnaire and gave it to each family with their child's "goody bag" at the end of the day. The questionnaire was completed within 24 hours by 16 of 29 families. Half the parents said that they had wanted another opinion, even though 13 valued seeing the same general practitioner or consultant for every appointment. Eight children had enjoyed the day, and 15 parents thought that the day had been worth while. But none of the parents thought that having another opinion was useful, and 14 didn't consider that they had learnt anything new. Eleven of the parents considered that they knew more about their child's condition than the candidate did.

In retrospect, I was naive to think that most parents don't want a second opinion. "It's possible that there's a doctor out there who has got the answer for my son," was one mother's view. A point that didn't get emphasised in Sayer et al's paper, however, was the freak show element. A teenager commented, "We're all here because we've got something wrong with us. And then those examiners don't pick you. That's even more humiliating because it means that you're not diseased enough."

So why did they put themselves through it? One reason given in all the replies was to educate doctors.

John Dearlove consultant paediatrician Yeovil District General Hospital, Yeovil BA21 4AT dearj@est.nhs.uk

1 Sayer M, Bowman D, Evans D, Wessier A, Wood D. Use of patients in professional medical examinations: current UK practice and the ethicolegal implications for medical education $B M J$ 2002.324:4047. (16 February)

\section{Recombinant human parathyroid hormone}

Preclinical data on rat osteosarcoma were not dismissed

EDITOR-As members of the United States Food and Drug Administration's division of metabolic and endocrine drug products responsible for the review of Eli Lilly's teriparatide $\left(\mathrm{PTH}_{1-34}\right)$ application, we would like to respond to Reeve's editorial on recombinant human parathyroid hormone. ${ }^{1}$ Although the administration's advisory committee concluded that the company provided sufficient evidence to support the efficacy of teriparatide in the treatment of postmenopausal osteoporosis and idiopathic and hypogonadal osteoporosis in men, the committee did voice concern about osteosarcomas that developed in rats treated with the drug.

In contrast to Reeve's assertion that rats received huge doses of teriparatide, some animals developed osteosarcomas when treated with doses that were approximately three times the expected daily human exposure-a small safety margin by conventional standards of drug development Although several factors limit the ability to extrapolate the rat findings to humans, we did not dismiss the preclinical data as clinically irrelevant and believe that they should be factored into the drug's profile of benefits versus risks. A complete discussion of teriparatide's efficacy and safety can be found in the transcript of the July 2001 meeting of the advisory committee of the Food and Drug Administration."

Gemma Kuijpers clinical pharmacology reviewer Bruce Schneider medical officer

Bruce Stadel medical officer

colmane@cder.fda.gov

US Food and Drug Administration, Center for Drug Evaluation and Research, Division of

Metabolic and Endocrine Drug Products, 5600 Fishers Lane, Rockville, MD 20857, USA

This letter expresses the views of the authors and does not necessarily reflect the official position of the US Food and Drug Administration.

1 Reeve J. Recombinant human parathyroid hormone. BMJ 2002;324:435-6. (23 February.)

2 Endocrinologic and Metabolic Drugs Advisory Committee meeting transcript. www.fda.gov/ohrms/dockets/ ac/01/transcripts/3761t2.htm (accessed 25 February).

\section{Author's reply}

EDITOR-Kuijpers et al are right to correct my editorial, which left my desk on 13 September 2001, when I was still relying on verbatim accounts of the Food and Drug Administration's hearing. The editorial's publication was a surprise: I had thought that, in the event of delayed publication, I would be allowed to correct and update it.

Osteosarcoma is an uncommon human tumour (up to 1500 cases annually in the United States), usually occurring before the age of 30, more often in males. ${ }^{1}$ It can also occur in Pagetic bone at older ages. Having asked the makers of teriparatide and those investigating related compounds, I know of no case of osteosarcoma being reported among around 2000 patients treated so far with parathyroid hormone or parathyroid hormone related protein analogue. Clearly, if teriparatide becomes licensed, patients should be followed clinically and through cancer registries to be sure that this carcinogenic effect in rats really is absent in patients. The low background incidence of osteosarcoma, especially in the age group likely to receive teriparatide, may make it more difficult for any carcinogenic effect to be detected. The opposite is likely to be the case for strictly mathematical reasons (since the variance in the observed difference between two quantities described by Poisson statistics is the sum of those quantities).

Since last year further information has emerged implying that the protective effect of teriparatide against fractures extends to men and that some protection in men and women continues after treatment is discontinued. ${ }^{23}$ There is reason at this stage to be hopeful about the prospects for controlling the effects of osteoporosis with this and other already established treatments. This is necessary because osteoporosis currently leads to the occurrence of one or more spine fractures in $40 \%$ of women and $20 \%$ of men by the age of $80 .{ }^{4}$ Only about $10 \%$ of these, by interpolation from a recent survey, ${ }^{5}$ become known in NHS primary care. This rate is unsatisfactory, not only because spine fractures can sometimes be exquisitely painful when they first occur but also because of their deleterious 
long term effects on quality of life and their prediction of future hip fractures.

Jonathan Reeve head, bone research group (MRC)
University Department of Medicine, Box 157 ,

Addenbrooke's Hospital, Cambridge CB2 2QQ

1 Whyte MP. Skeletal neoplasms. In: Favus MJ, ed. Primer on the metabolic bone diseases and disorders of skeletal metabolism. Philadelphia: Lippincott, Williams and Wilkins, 1999:397 405.

Kaufman JM, Scheele WH, Orwoll E, Clancy A D, Adami S, Syversen U, et al. Recombinant human parathyroid hormone (1-34) therapy increases bone mineral density and may decrease the risk of fractures in men with low bone density. Osteoporosis Int 2001;12(suppl 2):S13.

3 Eriksen EF, Lindsay R, Scheele WH, Clancy AD, Mitlak BH Incident vertebral fractures during an 18-month observation period following discontinuation of recombinant human parathyroid hormone (1-34) use in postmenopausal women with osteoporosis. Osteoporosis Int 2001;12(suppl 2):S46.

4 Felsenberg D, Silman AJ, Lunt M, Armbrecht G, Ismail AA, Finn JD, et al. Incidence of vertebral fraces in Eun inn JD, et al. Incidence of vertebral fractures in Europe: (EPOS)

5 Van Staa TP, Dennison EM, Leufkens HGM, Cooper C. Epidemiology of fractures in England and Wales. Bone Epidemiology of

\section{Misdiagnosis of epilepsy}

\section{Epilepsy care is deficient for both patients and doctors}

EDITOR-In their editorial on the misdiagnosis of epilepsy Chadwick and Smith seem to have missed the point. ${ }^{1}$ The diagnosis of epilepsy is often difficult and mistakes are often made (by specialists and nonspecialists), so an improvement in epilepsy services is imperative.

As the editorial says, there are only a derisory 62 paediatric neurologists in the United Kingdom; even at the maximal rate of recruitment to this specialty it will be at least 15 years before an appreciable proportion of children with epilepsy have an opportunity of meeting such a specialist, let alone being treated by him or her on a continuing basis.

The most important improvement in epilepsy services will therefore come from better training for general paediatricians and physicians, together with more effective ways in which they can share their difficult cases with specialist neurologists, who are usually based in tertiary centres. In addition, epilepsy support services provided by trusts, including neurophysiology, need to be radically improved.

None of this was available to Dr Andrew Holton in Leicester, whom Chadwick and Smith mention in the editorial. In the review into his work by the British Paediatric Neurology Association he was noted to be a hard working and conscientious doctor. ${ }^{2}$ It recommended that he should be returned to his post after six months of retraining. He was no doubt upset to be failing in the management of several of his patients but was without sufficient training, was overworked, waited far too long for electroencephalography to be performed, and was isolated without having any specialist support available at regional level.

Like many patients, Dr Holton has become a victim of the deficiencies in epilepsy care in the United Kingdom for children and adults. We certainly need more specialists, but we also need better training for generalists and better support for us all.

Richard Morton consultant paediatrician Children's Hospital, Derby DE22 3NE

1 Chadwick D, Smith D. The misdiagnosis of epilepsy. BMJ 2002;324:495-6. (2 March.)

Ro Sper College Specialty Advisory Committee in Paediatric Neurology. Solton, Leicest Royal Infirmary. London: RCPCH, 2001.

\section{Misdiagnosis occurs particularly in children}

EDITOR-The editorial by Chadwick and Smith on the misdiagnosis of epilepsy, although referring briefly to the misdiagnosis and mismanagement of epilepsy in children, clearly focuses on adults. ${ }^{1}$ The range of paroxysmal disorders occurring in children, which are often misdiagnosed as epileptic seizures, is far greater than that encountered in adults; they are more difficult to recognise and diagnose, particularly in children aged 10 and under. ${ }^{2}$

As Chadwick and Smith emphasise in the editorial, the diagnosis of epilepsy should be established on clinical grounds and based on a detailed witnessed account with or without the use of video recordings of the child's paroxysmal episodes. If it remains unclear whether the child is experiencing epileptic seizures, then epilepsy should not be diagnosed and the case should be discussed with a specialist who has a wider knowledge and experience of both the many different epilepsy syndromes and the other frequent paroxysmal disorders in childhood.

In the United Kingdom these specialists are paediatric neurologists, of whom there are fewer than one per million population. This number is wholly unacceptable, not just in addressing the needs of children with epilepsy and their families but also in supporting the needs of the paediatricians in district general hospitals, who tend to manage most of these patients and depend on their paediatric neurology colleagues for advice and guidance.

The editorial did not mention the role and specifically the misuse of electroencephalography in the misdiagnosis of epilepsy. Unfortunately, electroencephalography is often considered to be a definitive diagnostic test for epilepsy, but it rarely fulfils this perceived role. Furthermore, in many cases electroencephalography is undertaken and the scan reported by inexperienced and inadequately trained professionals who are unaware of the normal, maturational electroencephalographic patterns occurring in the first decade of life or the significance of specific abnormal patterns in electroencephalograms. Inadequate recording or inaccurate interpretation of the electroencephalogram, or both, contribute much to the misdiagnosis of epilepsy in children.

Children with epilepsy are being failed by the NHS, as are all children who have a neurological disorder and a neurodisability. As this letter is being read, somewhere in an outpatient clinic in the United Kingdom a child is being misdiagnosed as having epilepsy, being inappropriately investigated with electroencephalography, and being prescribed an unnecessary antiepileptic drug (probably in an inappropriate dose). The Leicester case cited by Chadwick and Smith is just one of many.

Richard E Appleton consultant paediatric neurologist Royal Liverpool Children's NHS Trust, Roald Dah EEG Unit, Alder Hey, Liverpool L12 2AP

Richard.Appleton@rlch-tr.nwest.nhs.uk

1 Chadwick D, Smith D. The misdiagnosis of epilepsy. BMJ 2002;324:495-6. (2 March.)

2 Gibbs J, Appleton RE. False diagnosis of epilepsy in children. Seizure 1992;1:15-8.

3 Daley HM, Appleton RE. Fits, faints and funny turns. Current Paediatrics 2000;10:22-7.

\section{0-minute consultation: Rhinitis}

\section{Referral to specialist otolaryngologist may be advisable}

EDITOR-Although the 10-minute consultation on rhinitis serves as a useful guide for treatment of this common condition, certain points merit clarification.

We agree that unilateral nasal blockage and bleeding warrant prompt referral since these symptoms may indicate an underlying malignancy. Contrary to the authors' suggestion, however, this is an uncommon presentation of nasopharyngeal carcinoma, which is more frequently associated with unilateral glue ear or cervical lymphadenopathy. Examination of the nose by an experienced doctor using adequate illumination is essential to exclude other diagnoses, such as septal deflection, turbinate enlargement, and nasal polyposis. We are also surprised that no mention is made of the diagnostic value of allergy testing, which has been shown to be feasible in primary care.

With regard to treatment, the authors do not emphasise that topical nasal decongestants such as oxymetazoline should be avoided in prolonged courses owing to the incidence of rebound oedema and rhinitis medicamentosa. ${ }^{3}$ We disagree with the assertion that steroid drops should not be used in chronic allergic rhinitis since they increase systemic absorption.

Betamethasone nasal drops do cause appreciable systemic bioavailability and in protracted regimens have been associated with undesirable side effects. This is not the case, however, with fluticasone nasal drops, which have negligible absorption $(0.06 \%)$, less even than fluticasone spray $(0.51 \%){ }^{4}$ Along with budesonide, they do not contain benzalkonium chloride preservative, which is found in most other topical preparations and to which some patients are sensitive. ${ }^{5}$ These preparations are therefore of particular use in patients developing nasal discomfort with more commonly prescribed sprays.

Either betamethasone or fluticasone nasal drops are preferable to the course of $20 \mathrm{mg}$ oral prednisolone suggested by the authors-a treatment rarely given for allergic rhinitis even by specialists. Equally, the authors are unwise to suggest referral for immunotherapy as a realistic option in primary care, since this controversial technique is used in only a few centres. 
We agree that many patients with allergic rhinitis can be treated successfully in primary care but believe that more emphasis should be placed on adequate initial examination of the patient and particularly on referral to a specialist otolaryngologist or allergist should initial treatment fail.

Natalie Brookes specialist registrar

Nataliebrookes@aol.com

Hesham Saleh consultant surgeon

Ian Mackay consultant surgeom

Department of Otorhinolaryngology, Charing

Cross Hospital, London W6 8RF

1 Walker S, Sheikh A. 10-minute consultation. Rhinitis. BMJ 2002;324:403. (16 February.)

2 Sibbald B, Barnes G, Durham SR. Skin prick testing in general practice: a pilot study. J Adv Nurs 1998;27:442-4.

general practice: a pilot study.J Adv Nurs 1998;27:442-4.

Graf P, Hallen H, Juto JE. Four-week use of oxymetazoline nasal spray (Nezeril) once daily at night induces rebound
swelling and nasal hypersensitivity. Acta Otolaryngol swelling and

4 Daley-Yates PT, Baker RC. Systemic bioavailability of fluticasone propionate administered as nasal drops and aqueous nasal spray formulations. BrJ Clin Pharmacol 2001;51:103-5

5 Hallen H, Graf P. Benzalkonium chloride in nasa decongestive sprays has a long-lasting adverse effect on nasal mucosa of healthy volunteers. Clin Exp Allergy 1995;25:401-5.

\section{Article is unhelpful}

EDITOR-The comment in the 10-minute consultation on rhinitis that unilateral nasal obstruction and bloodstained discharge is an alarm symptom of nasopharyngeal carcinoma is untrue. ${ }^{1}$ Unilateral nasal obstruction and nose bleeds are extremely common nasal symptoms, presenting either separately or together, and are usually due to a deviation of the nasal septum. The occasions on which they might be due to serious disease are vanishingly small. Furthermore, they are not symptoms of nasopharyngeal carcinoma: it tends to present as a unilateral serous otitis media.

In over seven years as a consultant head and neck surgeon, I have seen only two cases of sinonasal malignancy. In both, although nasal obstruction was present, it was not the presenting symptom: that was pain and facial swelling. There was no bleeding in either case.

The statement that patients with such symptoms warrant an urgent specialist opinion, without reference to the relative frequencies of the causative disease, is unhelpful and inappropriate.

Andrew McCombe consultant ear, nose, and throat and head and neck surgeon

Frimley Park Hospital, Camberley, Surrey

GU16 5UJ

AMcco79794@aol.com

1 Walker S, Sheikh A. 10-minute consultation. Rhinitis. BMJ 2002;324:403. (16 February.)

\section{Experienced based treatment of head lice}

EDITOR-Head lice are a familiar problem to most doctors, but especially to general practitioners and those who have children. Ten of the 17 responses to Dodd's editorial were from doctors, and all but four were from the United Kingdom. ${ }^{12}$ Many respondents enthusiastically described the strategies that had worked for their children, most favouring variations on the theme of wet combing, a strategy deemed ineffective in the editorial.
Robert Bunney, one of four general practitioners responding, reports that his children repeatedly required treatment, and although the infestations usually responded to various pediculicides, the children soon became reinfected. In exasperation he turned to wet combing and kept them clear until the epidemic waned. The combing method, he adds, although initially seeming to have less success than pediculicides, will at least retain or even increase its effectiveness as parents become more skilled in using it and realise that resistance can't occur.

C H Kimberley, another general practitioner, says: "We are regularly told that head lice only transfer on prolonged head to head contact, that head lice off the head lose their infectiveness, and that wet combing is ineffective. My son brought head lice home from school. We all used a permethrin lotion, following the manufacturer's instructions. It failed. We used wet combing with louse comb and conditioner, which succeeded.... Common sense suggests that regular bug busting (which, like the application of pesticides, needs to be done correctly) should be used."

Community Hygiene Concern (www.chc.org/bugbusting) provides kits and instructions at a reasonable cost. Product costs must be considered, writes Joanna Ibarra, programme coordinator for the charity. If chemicals are used each new case requires two doses. In contrast, a single bug buster can be used for the whole family, is reusable, and often leads to cure.

Dry combing with conditioner is advocated as the most effective way of finding and treating head lice in primary schoolchildren on Australian government website found by Phillip Colquitt (www.health.qld.gov.au/phs/ shpu/9169_doc.pdf). "Use enough conditioner to thoroughly cover the whole scalp and all hair from the roots to the tips."

Rowan Harwood, a consultant geriatrician, confirms that two applications each of phenothrin and permethrin to lice on his children's heads were ineffective, although they did seem to kill the adults. He was, however, unimpressed by the combing and conditioner regimen, especially in long hair, and resorted to picking out the juvenile lice by hand. "They are just visible to the naked eye and can be crushed between finger nails. It takes some forbearance on the part of the children"-on day 1 he retrieved 42 lice from one head, but by day 7 no more lice were appearing.

Jenny Muiry extols the virtues of using a fine tooth comb. But buyers beware: many combs are ineffective as they can extract only adult lice, and so nit combing is seen as ineffective. She has successfully used a two-piece comb (ITAX; Gadimex) that has barely any space between the teeth and can extract the smallest juvenile lice. She applies a simple protocol (wash hair and apply conditioner; brush and then comb hair thoroughly; rinse) every four days while there are still signs of nits (at least two weeks).

Gary Jackson, a public health doctor from New Zealand, urges discussion of the electronic comb, Robi Comb, which is pow-

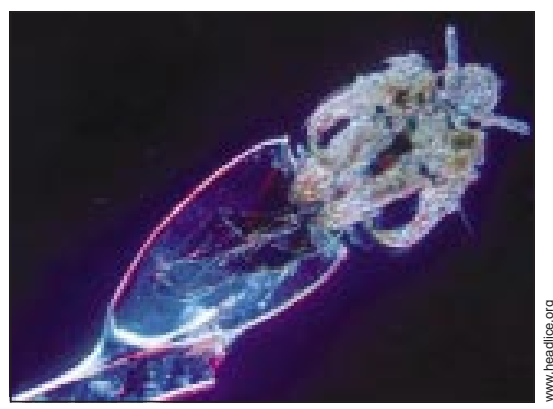

Some variant of wet combing may yet be the best way to zap me and mine

ered by a battery and proved effective for his children. It makes a humming sound until it finds a louse, at which point the louse is "zapped" and the humming stops. After the comb's teeth are cleaned the humming starts again and you can look for more lice.

No effectiveness trials for the electric comb are available yet, but at least one general practitioner, John Charlton, says that the few electric combs he has seen have failed miserably and are not a patch on combing (everyone) three times a day. Ms Ibarra and colleagues explain that their main drawback is that they must be used on dry hair for safety reasons and head lice move rapidly away from any disturbance in dry hair, thus evading the teeth. In addition, anything caught in the teeth, including scalp debris, will cut off the current, allowing lice in the vicinity to escape while the comb is cleaned.

The simplest and most effective treatment found by Wendy Taylor, a consultant neuroradiologist and veteran of multiple infestations in her three children, is a shampoo of tea tree oil followed by extraction of the nits with ordinary conditioner and a lice comb. "This should be repeated every two or three days for a week or so." Nigel Hill, a medical entomologist in London, has a word of warning, though. "Although many pharmacists advocate tea tree oil as a cure for lice, most are unaware that, volume for volume, it is more toxic to mammals than malathion."

Finally, Colin Dewar, a research psychiatrist, recommends an extremely short haircut, followed by a sponge over the scalp with methylated spirits. "Neat alcohol is highly toxic to arthropods, without causing any damage to the skin of humans when used occasionally." So not much has changed then since the shaved heads, shame, and nit picking of around 100 years ago.

Liz Crossan freelance technical editor

1 Dodd C. Treatment of head lice. BMJ 2001;323:1084. (10 November.)

2 Electronic responses. Treatment of head lice. bmj.com 2001. (www.bmj.com/cgi/eletters/323/7321/1084; accessed 8 May 2002.)

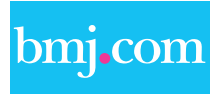

\section{Rapid responses}

Correspondence submitted electronically is available on our website 